\title{
Efficacy of amoxicillin-clavulanic acid versus ceftriaxone in children hospitalized under 5 years of age with uncomplicated community acquired pneumonia.
}

1. FCPS (Paediatrics Medicine) Senior Registrar Paediatrics Medicine

2. FCPS (Paediatrics Medicine) Assistant Professor Paediatrics Medicine

3. FCPS (Paediatrics Medicine) Senior Registrar Paediatrics Medicine

4. FCPS (Paediatrics Medicine) Senior Registrar Paediatrics Medicine

5. FCPS (Paediatrics Medicine) Associate Professor \& Head Paediatrics Emergency (M4)

$1,2,3,4,5$

The Children Hospital and Institute of Child Health, Lahore.

Correspondence Address:

Dr. Huriya Abid

Department of Paediatrics Medicine

The Children Hospital and

Institute of Child Health, Lahore.

huriyaabid.ha@gmail.com

Article received on:

19/02/2020

Accepted for publication:

$13 / 04 / 2020$

\begin{abstract}
Huriya Abid', Wajiha Rizwan², Irfan Naeem ${ }^{3}$, Aysha Mansoor Lodhi ${ }^{4}$, Muhammad Nasir Rana ${ }^{5}$
\end{abstract}
ABSTRACT... Objectives: The aim of current study was to compare efficacy of amoxicillinclavulanic acid versus ceftriaxone among children under 5 years of age, hospitalized having uncomplicated CAP. Study Design: Randomized Controlled trial (RCT). Setting: Department of Pediatric Medicine, The Children Hospital and Institute of Child Health, Lahore. Period: 01/01/2019 to 30/06/2019. Material \& Methods: A total of 210 (105 in each group) children aged between 2 to 60 months, diagnosed having CAP were randomly allocated into either Group-A (received IV amoxicillin-clavulanic acid) or Group B (received IV ceftriaxone). Efficacy in terms of response of both treatment groups was noted after 5 days treatment. Results: Overall, mean age was noted as $14.68 \pm 15.7$ months. Majority $(n=131,32.4 \%)$ were male and aged between 1 to 12 months $(n=135,64.3 \%)$. Mean duration of symptoms was noted as $3.60 \pm 1.69$ days. Efficacy was significantly higher in children treated with ceftriaxone as compared to those treated with Amoxicillin/Clavulanic acid (96.2\% vs. $76.2 \% ; p<0.001)$. This difference was significant across all age, gender and duration of symptom groups $(p<0.05)$. Conclusion: The efficacy was significantly higher in children treated with ceftriaxone as compared to Amoxicillin/ Clavulanic acid.

Key words: $\quad$ Amoxicillin, Ceftriaxone, Community Acquired Pneumonia, Efficacy.

Article Citation: Abid H, Rizwan W, Naeem I, Lodhi AM, Rana MN. Efficacy of amoxicillinclavulanic acid versus ceftriaxone in children hospitalized under 5 years of age with uncomplicated community acquired pneumonia. Professional Med J 2020; 27(11):2339-2344. https://doi.org/10.29309/TPMJ/2020.27.11.4582

\section{INTRODUCTION}

Pneumonia is described as an inflammation of the parenchyma of the lungs. ${ }^{1}$ Pneumonia is killing more children than any other type of infectious disease. Every year, pneumonia is estimated to claim the lives of more than 800,000 children under the age of 5 years. Greatest incidence of pneumonia is observed among South Asian countries where 2500 per 100000 children are affected with it. ${ }^{2,3}$ In Pakistan, pneumonia is the leading reason of mortality among children, contributing to $33 \%$ of all deaths in infants and $37 \%$ of all deaths in children 1 to 4 years. ${ }^{4}$ It has also been estimated that around $70 \%$ of global under 5 years of age deaths are being reported from only 15 countries while about $50 \%$ from 5 countries (that includes Pakistan as well). ${ }^{5}$ According to UNICEF, in 2018, an estimated 58000 children died due to pneumonia in Pakistan. ${ }^{2}$
Under the age of 5 years, around 1 out of 500 children are hospitalized every year having community acquired pneumonia (CAP). ${ }^{6}$ CAP may be caused by many pathogens yet commonest are known to be bacteria and viruses. In children less than 2 years of age, viral pathogens are more common while bacterial infections are more frequently seen among older children. In developing countries, streptococcus pneumonia is noted to be the commonest cause among children less than 5 years of age, followed by haemophilus influenza type b (Hib) and respiratory syncytial virus (RSV). ${ }^{7}$

WHO emphasized early diagnosis as well as assessment of severity of pneumonia based on clinical grounds and endorse antibiotics as foundation of treatment in suspected cases of bacterial CAP. Cotrimoxazole, penicillins, macrolides, aminoglycosides and cephalosporins 
are some of the most commonly used antibiotics regarding CAP.8,9 For in-patient management of CAP, WHO recommends amoxicillin (or benzylpenicillin)-gentamicin as $1^{\text {st }}$ line of treatment while ceftriaxone, cloxacillin and gentamicin are endorsed as $2^{\text {nd }}$ line treatment options. ${ }^{10}$

A study comparing ceftriaxone and amoxicillinCA monitoring resolution of symptoms of pneumonia, clinical cure rate and therapy failure noted cure rate of $97 \%$ with the use of ceftriaxone while amoxicillin-CA resulted in $88 \%$ of cure rate at the end of the treatment period. The difference was not statistically significant between both treatment groups for cure rates. ${ }^{11}$

To the best of our knowledge, no local study is available comparing efficacy of ceftriaxone and amoxicillin-CA in children having CAP so this study was conducted to compare efficacy of amoxicillin/clavulanic acid versus ceftriaxone among children under 5 years of age, hospitalized having uncomplicated CAP.

\section{MATERIAL \& METHODS}

This randomized controlled trial (RCT) was done at the Pediatric Medicine Ward, The Children Hospital and Institute of Child Health, Lahore, from $01 / 01 / 2019$ to $30 / 06 / 2019$.

Written informed consent was taken from parents/ guardians of all the study participants. Approval from Institutional Ethical Committee was taken for this trial. No conflict of interest was involved in this study and no financial grant or support was taken from the institution or any pharmaceutical company.

A sample of size of 210 (105 in each group) was calculated taking $80 \%$ power of test, $5 \%$ level of significance, and by taking expected efficacy of Ceftriaxone as $97 \%$ and Amoxicillin/CA as $88 \% .^{12}$

Study participants were children of both genders, aged 2 months to 5 years, having CAP and admitted through OPD and Emergency department in pediatric ward. CAP was labeled as per WHO guideline ${ }^{13}$ as no hospitalization in the last 1 month, presence of consolidations or other infiltrates, on chest $x$-ray and the presence of minimum one out of the following: I) fever, II) cough, III) respiratory rate $>50$ per minute in 2 months to 11 months of age, > 40 above 12 months to 59 months of age, IV) chest in-drawing, V) crepitation or wheeze on auscultation. Uncomplicated CAP was defined as CAP without complications on imaging study i.e. pnemothorax or blunting of costophrenic angles (air-fluid level) or necrosis on chest X-Ray. Children requiring intensive care unit (having cyanosis spO2 $<85 \%$ requiring intubation within first 24 hours of admission, having hospital-acquired pneumonia (that develops within 48 hours of admission), or with conditions like congenital heart or lung diseases, chronic kidney disease, developmental delays, severe malnutrition, asthma, immunodeficiency, already taking antibiotics, or having sign and symptoms related to system other than respiratory, were excluded from this study.

All the patients were divided into 2 groups adopting computer generated random numbers. Group-A received IV amoxicillin/CA as dose of $100 \mathrm{mg}$ per $\mathrm{kg}$ per day in 3 divided doses) while Group-B received IV ceftriaxone as dose of $75 \mathrm{mg}$ per $\mathrm{kg}$ per day in 2 divided doses. Total period for receiving study drug was 5 days. Response to treatment was assessed after 5 days and efficacy was labeled as absence of CAP (as per operational definition). All study information was recorded on a predesigned proforma.

All the collected data was analyzed employing SPSS version 24.0. Quantitative variables like age (months) and duration of symptoms (days) was presented in terms of mean and standard deviation (SD) while qualitative variables like gender and efficacy were presented in terms of frequency and percentages. Chi square test was applied to compare the qualitative variables while student's t-test was applied to compare age. P value less than or equal to 0.05 was taken as significant.

\section{RESULTS}

Out of total 205 study participants, age ranged between 2-60 months while mean age was $14.68 \pm 15.66$ months. Majority $(n=135,64.3 \%)$ 
of the patients were aged between 1-12 months followed by $1-3$ years $(n=47,22.4 \%)$ and $3-5$ years $(n=28,13.3 \%)$. There were $131(62.4 \%)$ male and $79(37.6 \%)$ female, representing a male to female ratio of 1.66 . Amongst all, duration of symptoms ranged from 1 day to 7 days and mean as $3.60 \pm 1.69$ days. No significant difference was noted between both study groups regarding baseline characteristics (Table-I).

The frequency of efficacy was significantly higher in children treated with ceftriaxone $(96.2 \%$ vs. $76.2 \%$; $p<0.001$ ) in comparison to those treated with Amoxicillin/CA. The difference was significant across all age, gender and duration of symptom groups (Table-II).

\section{DISCUSSION}

High prevalence of CAP among children emphasizes clinicians to always update their knowledge about the current trends and efficacy of antibiotics used for treating CAP. As no previous study has been conducted in Pakistan to compare the efficacy of ceftriaxone and amoxicillin-CA in children with CAP, aged less than 5 years, this study was planned to help clinicians for choosing a better option.

In the present study, overall mean age was $14.68 \pm 15.66$ months. Munir $S^{14}$ in a local study reported similar mean age of $13.78 \pm 12.06$ months among children presenting with CAP at Pakistan Institute of Medical Sciences (PIMS), Islamabad.

\begin{tabular}{|c|c|c|c|c|}
\hline Characteristics & Total $(n=210)$ & Group-A $(n=105)$ & Group-B $(n=105)$ & P-Value \\
\hline Age (months), Meand+SD & $14.68+15.7$ & $14.47+15.6$ & $14.90+15.8$ & 0.843 \\
\hline $\begin{array}{l}\text { Age Groups } \\
2-12 \text { months } \\
1-3 \text { years } \\
3-5 \text { years }\end{array}$ & $\begin{array}{l}135(64.3 \%) \\
47(22.4 \%) \\
28(13.3 \%)\end{array}$ & $\begin{array}{l}68(64.8 \%) \\
24(22.9 \%) \\
13(12.4 \%)\end{array}$ & $\begin{array}{l}67(63.8 \%) \\
23(21.9 \%) \\
15(4.3 \%)\end{array}$ & 0.918 \\
\hline $\begin{array}{l}\text { Gender } \\
\text { Male } \\
\text { Female }\end{array}$ & $\begin{array}{l}131(62.4 \%) \\
79(37.6 \%)\end{array}$ & $\begin{array}{l}66(62.9 \%) \\
39(37.1 \%)\end{array}$ & $\begin{array}{l}65(61.9 \%) \\
40(38.1 \%)\end{array}$ & 0.887 \\
\hline $\begin{array}{l}\text { Duration of Symptoms } \\
\text { (days), Mean }+\mathrm{SD}\end{array}$ & $3.60+1.69$ & $3.60+1.71$ & $3.59+1.61$ & 0.968 \\
\hline $\begin{array}{l}\text { Duration of Symptoms } \\
1-3 \text { days } \\
4-7 \text { days }\end{array}$ & $\begin{array}{l}107(51.0 \%) \\
103(49.0 \%)\end{array}$ & $\begin{array}{l}54(51.4 \%) \\
51(48.6 \%)\end{array}$ & $\begin{array}{l}53(50.5 \%) \\
52(49.5 \%)\end{array}$ & 0.890 \\
\hline
\end{tabular}

Table-I. Baseline characteristics of study participants.

\begin{tabular}{|l|c|c|c|c|}
\hline \multicolumn{1}{|c|}{ Characteristics } & Total $\mathbf{n}(\%)$ & Group-A $(\mathbf{n = 1 0 5})$ & Group-B (n=105) & P-Value \\
\hline Overall & $181 / 210(86.2 \%)$ & $80 / 105(76.2 \%)$ & $101 / 105(96.2 \%)$ & $<0.001$ \\
\hline Age Groups & & & & \\
2-12 months & $116 / 135(85.9 \%)$ & $52 / 68(76.5 \%)$ & $64 / 67(95.5 \%)$ & 0.001 \\
$\begin{array}{l}\text { 1-3 years } \\
\text { 3-5 years }\end{array}$ & $40 / 47(85.1 \%)$ & $18 / 24(75.0 \%)$ & $22 / 23(95.7 \%)$ & 0.047 \\
\hline Gender & $25.28(89.3 \%)$ & $10 / 13(76.9 \%)$ & $15 / 15(100 \%)$ & 0.049 \\
\hline $\begin{array}{l}\text { Male } \\
\text { Female }\end{array}$ & $112 / 131(85.5 \%)$ & $50 / 66(75.8 \%)$ & $62 / 65(95.4 \%)$ & 0.001 \\
\hline Duration of Symptoms & $69 / 79(87.3 \%)$ & $30 / 39(76.9 \%)$ & $39 / 40(97.5 \%)$ & 0.006 \\
\hline $\begin{array}{l}\text { 1-3 days } \\
\text { 4-7 days }\end{array}$ & $92 / 107(86.0 \%)$ & $41 / 54(95.9 \%)$ & & 0.002 \\
\hline
\end{tabular}


Dinur-Schejter $Y$ et al $^{12}$ noted similar mean age of $14.2 \pm 4.4$ months among such children. Relatively higher mean age of $29.7 \pm 8.9$ months months was reported previously by Hassan $\mathrm{M}$ et $\mathrm{al}^{15}$ in a local finding. Majority $(n=135,64.3 \%)$ of our patients were aged between 1-12 months followed by $1-3$ years $(n=47,22.4 \%)$ and $3-5$ years $(n=28$, $13.3 \%)$. Our findings were similar to what Bari A et $\mathrm{al}^{16}$ reported where frequency of age groups 2-12 months $(74.9 \%), 1-3$ years $(20.6 \%)$ and $3-5$ years (4.5\%). Hassan $\mathrm{M}$ et $\mathrm{al}^{15}$ (51.57\%), Hamid $\mathrm{MH}$ et al $^{17}(46 \%)$ and Simbalista $R$ et al ${ }^{18}(24.7 \%)$ also reported 2-12 months being the most frequent age group among children with CAP.

We noted majority, $62.4 \%$ of the patients to be male giving a male to female ratio of 1.7:1 which was very similarly to Bari $A$ et $\mathrm{al}^{16}(2: 1)$, Munir $\mathrm{S}^{14}$ (1.8:1), Simbalista $R$ et $a^{18}(1.5: 1)$ and Hamid $\mathrm{MH}$ et $\mathrm{al}^{17}(1.2: 1)$. Hassan $\mathrm{M}$ et $\mathrm{al}^{15}$ found much higher male predominance with a male to female ratio of 3:1 while Amir $\mathrm{J}$ et al ${ }^{19}$ reported a female prominence with a male to female ratio of 1:1.6. Our results stood similar to most findings with regards to age ${ }^{14-17}$ and gender ${ }^{16-18}$ distribution.

Overall, mean duration of symptoms was noted as $3.60 \pm 1.69$ days. A similar mean duration of symptoms before presentation at hospital has been reported by Dinur-Schejter $Y$ et al ${ }^{12}(3.5 \pm 2.9$ days) and Munir $\mathrm{S}^{14}$ (4.5 \pm 3.10 days).

As no significant difference was seen among participants of both study groups, so randomization proved effective without showing any sort of bias in between both the groups.

A study from Bangladesh ${ }^{20}$ noted ceftriaxone to be the most common antibiotic used in about $50 \%$ of the admitted children having pneumonia. Ceftriaxone seem to be a popular choice for treating pneumonia in this region. In the present study, the frequency of efficacy was significantly higher in children treated with ceftriaxone $(96.2 \%$ vs. $76.2 \%$; $p<0.001$ ) in comparison to Amoxicillin$\mathrm{CA}$. This difference was significant across all age, gender and duration of symptom groups. Amir $\mathrm{J}$ et $\mathrm{al}^{19}$ observed efficacy of amoxicillin-CA to be $88.0 \%$. However, the researchers only had a total of 62 patients in two study groups assessing different drugs. The observed difference in their series could be due to very limited sample size of study $(n=62)$ as compared to the present study $(n=210)$ which make current research more reliable. Similar to current findings, Zarinfar N et al from Iran $^{21}$ reported similar findings where they reported efficacy of amoxicillin-CA to be $79 \%$ in CAP. They however only included adult patients of community acquired pneumonia with a mean age of $48.12 \pm 17.96$ years. In a local RCT from Lahore ${ }^{22}$, IV ceftriaxone was compared with IV penicillin for children admitted with CAP. Ceftrixone showed significantly better efficacy than the comparator $(84.7 \%$ versus $71.8 \%, p=$ 0.04). Cetinkaya $\mathrm{F}$ et $\mathrm{al}^{23}$ found ceftriaxone to be equally effective when compared to a combination of parenteral penicillin and chloramphenicol.

A study done by Salih $\mathrm{KM}$ et al ${ }^{24}$ treating patients with CAP, noted efficacy of amoxicillin-CA, ceftriaxone and penicillin as $86 \%, 90 \%$ and $79 \%$. Those results supported that ceftriaxone was the most effective drug for the treatment of CAP while Roson $B$ et al recorded efficacy of ceftriaxone to be $88.9 \% .^{25}$

The present study is the first research aimed at finding our experience of studied drugs in the local population. Good sample size is the strength of this study while randomization showed no bias. A limitation to the present study was that we did not evaluate side effects of treatment which could be important and need to be considered in future studies.

\section{CONCLUSION}

Among children with CAP, efficacy was significantly higher in children treated with ceftriaxone in comparison to amoxicillin/clavulanic acid. This difference was significant across all age, gender and duration of symptom groups.

\section{Copyright(C) 13 Apr, 2020.}

\section{REFERENCES}

1. Mathur S, Fuchs A, Bielicki J, Anker JV, Sharland M. Antibiotic use for community-acquired pneumonia in neonates and children: WHO evidence review, Paediatrics and International Child Health 2018; 38(Sup1):S66-S75. 
2. UNICEF analysis, based on the United Nations interagency group for child mortality estimation estimates for the year 2018 and WHO and Maternal and Child Epidemiology Estimation Group (MCEE) interim estimates. 2019. Available from: https://childmortality. org/wp-content/uploads/2019/10/UN-IGME-ChildMortality-Report-2019.pdf.

3. Sulistyawati S, Sofiana L, Amala SK, Rokhmayanti R, Astut FD, Nurfita D. Pneumonia a neglected disease: A mixed-method study on the case-finding program in Indonesia. AIMS Public Health, 2020, 7(1): 81-91.

4. Aga Khan Health Service Pakistan. 2001 Annual Report, Northern Areas and Chitral Programme.

5. Lozano R, Naghavi M, Foreman K. Global and regional mortality from $\mathbf{2 3 5}$ causes of death for 20 age groups in 1990 and 2010: A systematic analysis for the Global Burden of Disease Study 2010. Lancet 2012; 380:2095-128.

6. McCulloh RJ, Patel K. Recent developments in pediatric community-acquired pneumonia. Curr Infect Dis Rep. 2016; 18:204.

7. WHO (2019) Pneumonia. Available from: https://www. who.int/news-room/fact-sheets/detail/pneumonia.

8. Nascimento-Carvalho CM. Community-acquired pneumonia among children: The latest evidence for an updated management. J Pediatr (Rio J). 2019; 822.

9. Nguyen PT, Tran HT, Fitzgerald DA, Tran TS, Graham SM, Marais BJ. Characterization of children hospitalized with pneumonia in central Vietnam: A prospective study. Eur Respir J. 2019 Jul 11; 54(1).

10. Usonis V, Ivaskevicius $\mathrm{R}$, Diez-Domingo J, Eposito S, Falup-Pecurariu OG, Finn A, et al. Comparison between diagnosis and treatment of communityacquired pneumonia in children in various medical centers across Europe with the United States, United Kingdom and the World Health Organization guidelines. Pneumonia (Nathan). 2016; 8:5.

11. WHO. Pocket Book of hospital care for children. Guidelines for the management of common illnesses with limited resources. Second edition. Geneva: World Health Organization; 2013. p. 80-91.

12. Dinur-Schejter $\mathrm{Y}$, Cohen-Cymberknoh $\mathrm{M}$, Tenenbaum A, Brooks R, Averbuch D, Kharasch S, et al. Antibiotic treatment of children with community-acquired pneumonia: Comparison of penicillin or ampicillin versus cefuroxime. Pediatr Pulmonol 2013; 48(1):52-8.
13. Wetzke M., Kopp M.V, Seidenberg J, Vogelberg C, Ankermann T, Happle C, et al. PedCAPNETZ prospective observational study on community acquired pneumonia in children and adolescents. BMC Pulm Med 2019; 19:238.

14. Munir S. Acute respiratory infection among children aged 2 month to 5 years: do children with initially "no pneumonia" progress to pneumonia? Ann Pak Inst Med Sci 2009; 5(3):154-7.

15. Hassan M, Faiz N. Atypical pneumonia in children in Islamabad: Clinical features and response to macrolides. Ann Pak Inst Med Sci 2009; 5(2):70-3.

16. Bari A, Zafar A, Mushtaq A, Ahmad TA, Ejaz I, Ejaz $H$. Disease pattern and bacteriological profile of childhood pneumonia. Pak Pediatr J 2014; 38(1):4752.

17. Hamid MH, Malik MA, Masood J, Zia A, Ahmad TA. Community acquired pneumonia in children. $\mathrm{J}$ Coll Physicians Surg Pak 2012; 22(3):155-8.

18. Simbalista $R$, Araujo $M$, Nascimento-Carvalho CM. Outcome of children hospitalized with communityacquired pneumonia treated with aqueous penicillin G. Clinics 2011;66(1):95-100.

19. Amir J, Harel L, Eidlitz-Markus T, Varsano I. Comparative evaluation of Cefixime versus AmoxicillinClavulanate following Ceftriaxone therapy of pneumonia. Clin Pediatr (Phila) 1996; 35(12):629-33.

20. Rashid M, Chisti MJ, Akter D, Sarkar M, Chowdhury F. Antibiotic use for pneumonia among children underfive at a pediatric hospital in Dhaka city, Bangladesh. Patient Preference and Adherence 2017:11; 1335-42.

21. Zarinfar N, Sarmadian H, Esmaeili A. Clinical efficacy of cefixim compared to amoxicillin-clavulanate in community acquired pneumonia treatment. Afr $\mathrm{J}$ Pharm Pharacol 2012; 6(47):3242-5.

22. Waqas M, Rehman A, Ubaidullah. Comparative efficacy of ceftriaxone versus penicillin in the treatment of children with severe community acquired pneumonia (CAP). Biomed J Sci \& Tech Res 2019; 14(4). BJSTR. MS.ID.002593.

23. Cetinkaya F, Gogremis A, Kutluk G. Comparison of two antibiotic regimens in the empirical treatment of severe childhood pneumonia. Indian J Pediatr 2004; 71(11):969-2.

24. Salih KM, Bilal JA, Eldouch W, Abdin A. Assessment of treatment of community acquired severe pneumonia by two different antibiotics. J Clin Diag Res 2016; 10(5): SC06-SC9. 
25. Roson B, Carratala J, Tubau F, Dorca J, Linares J, Pallares R, et al. Usefulness of betalactam therapy for community-acquired pneumonia in the era of drugresistant Streptococcus pneumoniae: A randomized study of amoxicillin-clavulanate and ceftriaxone. Microbial drug resistance (Larchmont, NY) 2001; $7(1): 85-96$.

\begin{tabular}{|c|c|c|c|}
\hline \multicolumn{4}{|c|}{ AUTHORSHIP AND CONTRIBUTION DECLARATION } \\
\hline Sr. \# & Author(s) Full Name & Contribution to the paper & Author(s) Signature \\
\hline 1 & Huriya Abid & $\begin{array}{l}\text { Literature Search, Introduction, } \\
\text { Data Interpretation. }\end{array}$ & \\
\hline 2 & Wajiha Rizwan & $\begin{array}{l}\text { Study idea, Methodology, } \\
\text { Drafting. }\end{array}$ & wighers \\
\hline 3 & Irfan Naeem & Data collection, Data analysis. & \\
\hline 4 & Aysha Mansoor Lodhi & Data collection, Data analysis. & \\
\hline 5 & Muhammad Nasir Rana & Supervision, Proof reading. & mans \\
\hline
\end{tabular}

